Pao-Ping Lu MD,

Chen-Hsien Yang MD,

Angie C.Y. Ho MD,

Ming-Hwang Shyr MD PhD

\section{The intubating LMA: a comparison of insertion techniques with conven- tional tracheal tubes}

Purpose: To compare the performance of the intubating laryngeal mask airway (ILMA) in assisting blind tracheal intubation with conventional tracheal tubes of different curvatures and the frequency of possible associated complications.

Methods: After informed consent, 240 ASA I-II adults undergoing elective surgery participated in a randomized, single blind clinical trial to receive blind trachea intubation via ILMA with a conventional tracheal tube curved with normal (Normal group) or reversed (Reverse group) direction. More than three attempts at intubation was regarded as failure. The lowest oxygen saturation during intubation was recorded and postintubation sore throat and hoarseness were evaluated with verbal analog scales.

Results: The overall success rates of intubation with Normal and Reverse groups were not different $(96.7 \%$ and $94.2 \%$ respectively). Successful intubation at the first attempt was higher in the Reverse group than in the Normal group $(86.7 \%$ vs $75.0 \%, P=0.033)$. The incidence of sore throat was higher in the Normal group than in the Reverse group (19.2\% vs $9.2 \%$ respectively, $P=0.042$ ).

Conclusions: Blind trachea intubation via an ILMA with the conventional curved tracheal tube is feasible and highly successful. Reverse curve direction is preferable at the first attempt of intubation for its higher success rate and lower incidence of complications.

Objectif : Comparer le fonctionnement du masque laryngé d'intubation (MLI) utilisé avec des tubes endotrachéaux de différentes courbures, pour faciliter l'intubation endotrachéale à l'aveugle, et la fréquence de complications possibles.

Méthode : Ayant donné leur consentement éclairé, 240 adultes d'état physique ASA I-II devant subir une intervention planifiée ont participé à un essai clinique randomisé et à l'insu. L'intubation, à l'aveugle avec le MLI et un tube endotrachéal de courbure habituelle (groupe normal) ou par insertion inversée (groupe inversé), était notée comme un échec si elle exigeait plus de trois essais. On a enregistré la plus faible saturation en oxygène pendant l'intubation et évalué, selon une échelle verbale analogique, le mal de gorge et la raucité de la voix qui ont pu suivre l'intubation.

Résultats : Le taux de succès de l'intubation n'a pas présenté de différence intergroupe significative $(96,7 \%$ et $94,2 \%$ respectivement). Une intubation réussie au premier essai a été plus fréquente dans le groupe inversé que dans le groupe normal $(86,7 \%$ vs $75,0 \%, P=0,033)$. L'incidence de mal de gorge a été plus élevée dans le groupe normal que dans le groupe inversé $(19,2 \%$ vs $9,2 \%$ respectivement, $P=0,042)$.

Conclusion : L'intubation endotrachéale à l'aveugle avec un MLI et un tube endotrachéal de courbure habituelle est possible et fréquemment réussie. L'insertion par inversion de la courbure, préférable au premier essai d'intubation, présente un meilleur taux de réussite et moins de complications.

From the Department of Anaesthesia, Chang Gung Memorial Hospital, 5 Fu-hsing Street, Kwei-shan, Taoyuan 333, Taiwan, Republic of China.

Address correspondence to: Ming-Hwang Shyr MD PhD, Phone: 886-3-3281200, Ext. 2324; Fax: 886-3-3342068;

E-mail: an001@adm.cgmh.com.tw

Accepted for publication March 19, 2000. 
$\mathrm{F}$

AILED or difficult tracheal intubation occurs infrequently but it remains the most important cause of mortality and morbidity in anesthesia. ${ }^{1}$ The standard laryngeal mask airway, first described in 1985 by Brain, ${ }^{2}$ has been shown to play an important role in rescue ventilation ${ }^{3}$ in difficult airway management but its role in facilitating tracheal intubation is limited. The recently introduced intubating laryngeal mask airway (ILMA) is a form of laryngeal mask airway designed to facilitate tracheal intubation with a tracheal tube. There have been many reports regarding successful intubation via the ILMA in cases of unanticipated and anticipated difficult airway. ${ }^{4-7}$

Reported success rates of blind tracheal intubation via the ILMA have varied between $89.5-100 \% .{ }^{8-11}$ The preliminary study reported by Brain et al. ${ }^{11}$ utilized a straight, reusable silicone tracheal tube (Accusil Inc, IN, USA). Successful tracheal intubation via the ILMA using a conventional polyvinyl chloride tracheal tube has been reported by many authors. ${ }^{4,8-10}$ Joo \& Rose 12 advocate tracheal intubation via ILMA with the tracheal tube inserted in a reversed curve, instead of the conventional normal curve, but there has been no controlled comparative study.

We embarked on a prospective study to investigate the success rate of blind tracheal intubation via an ILMA with different curve directions of a conventional tracheal tube, and to examine the associated complications.

Methods

Two hundred and forty patients aged over $18 \mathrm{yr}$, ASA physical status I or II, were studied after hospital ethics committee approval and written informed consent. Exclusion criteria included Mallampati scores > 3 , morbid obesity, respiratory tract (oropharynx, larynx) pathology, limited mouth opening (interdental gap $<2 \mathrm{~cm}$ ), risk of regurgitation or aspiration (previous upper gastrointestinal tract surgery, known or symptomatic hiatus hernia, esophageal reflux, peptic ulceration or not fasted).

Anesthetic management was standardized. Monitoring was applied pre-induction and included an electrocardiograph, pulse oximeter, capnograph and noninvasive blood pressure monitor. The head and neck of patients were placed in a neutral position. Patients were pre-oxygenated and anesthesia was induced with 4$6 \mathrm{mg} \cdot \mathrm{kg}^{-1}$ thiopental, 3-5 $\mu \mathrm{g} \cdot \mathrm{kg}^{-1}$ fentanyl and muscular relaxation was facilitated with $0.5 \mathrm{mg} \cdot \mathrm{kg}^{-1}$ atracurium $i$. The ILMA (LMA-Fastrach ${ }^{\mathrm{TM}}$, The Laryngeal Mask Company Ltd, United Kingdom) was inserted when the jaw was relaxed, the eyelash reflex absent and the patient apneic. The size \#4 ILMA was the initial choice for men weighing $>75 \mathrm{~kg}$ and the size \#3 was selected for all women and men $<75 \mathrm{~kg}$. After insertion, using a handheld cuff inflator-manometer, the ILMA was inflated to an intracuff pressure of $60-70 \mathrm{~cm} \mathrm{H}_{2} \mathrm{O}$. Optimal ILMA position was judged by chest wall movement and $\mathrm{CO}_{2}$ exchange on capnograph during gentle manually assisted ventilation. The operator was allowed to change to another size of ILMA or make necessary ILMA adjustments (pull-up or push-down, rightward or leftward rotation) if ventilation was not satisfactory. Following lubrication with a bolus of water-soluble jelly (K-Y lubricating jelly, Johnson \& Johnson), a conventional tracheal tube (Sheridan ${ }^{\circledR}$ tracheal tube, The Kendall Company, USA) was inserted with the selected curvature and passed into the trachea via the ILMA. A tracheal tube of $7.0 \mathrm{~mm}$ I.D. was selected for women and $7.5 \mathrm{~mm}$ I.D. tracheal tube for men. During the attempt of intubation, patient was kept anesthetized with volatile anesthetics in $100 \% \mathrm{O}_{2}$. Successful tracheal intubation was confirmed by $\mathrm{CO}_{2}$ exchange on capnograph. Following successful tracheal intubation, the ILMA was removed and the tracheal tube was left in situ.

All ILMA placements and tracheal intubations were performed by the same staff anesthesiologist who had placed the ILMA on fewer than 10 occasions before the study commenced. Patients were randomly assigned into two groups: Normal and Reverse groups. In each patient intubation via the ILMA was limited to three attempts. Intubation proceeded with the tracheal tube inserted in the same selected curvature (normal curve in Normal group and reversed curve in Reverse group) for the first two attempts. The third attempt at intubation, when required, used the opposite curve. Following each failed intubation, the position of the ILMA was adjusted if necessary.

The lowest oxygen saturation during the procedure was recorded. Post-intubation sore throat and hoarseness were evaluated by verbal analog scales (VAS) on visit the next day. A VAS > 3 was considered clinically significant.

The success rates of blind tracheal intubation via ILMA in Normal and Reverse groups were compared using the chi-square test with Yates correction. Intergroup and intra-group comparisons were analyzed. The incidences of sore throat and hoarseness were also analyzed with chi-square test with Yates correction. A $P<0.05$ was considered statistically significant.

Results

Demographic data are presented in Table I. Mean age and weight were $44 \pm 17$ (range 18-84) yr and $62 \pm 11$ (35$95) \mathrm{kg}$ respectively. The male:female ratio was $152: 88$. 
TABLE I Demographic data

\begin{tabular}{lll}
\hline & Normal group & Reverse group \\
\hline Sex $($ Male/Female $)$ & $79 / 41$ & $73 / 47$ \\
Age $(\mathrm{yr})$ & $43 \pm 17$ & $45 \pm 18$ \\
Weight $(\mathrm{kg})$ & $62 \pm 12$ & $62 \pm 11$ \\
\hline
\end{tabular}

All values are means $\pm \mathrm{SE}$

No significant difference between groups.

TABLE II Success rates of blind tracheal intubation via LMAFastrach $^{\mathrm{TM}}$ using conventional tracheal tube inserted in normal and reversed direction.

\begin{tabular}{lll}
\hline & Normal group & Reverse group \\
\hline Total success & $96.7 \%(116 / 120)$ & $94.2 \%(113 / 120)$ \\
First attempt & $75.0 \%(90 / 120)$ & $86.7 \%^{*}(104 / 120)$ \\
Second attempt & $40.0 \%(12 / 30)$ & $18.8 \%(3 / 16)$ \\
Third attempt & & \\
(Opposite direction) & $77.8 \% \dagger(14 / 18)$ & $46.2 \%(6 / 13)$ \\
\hline
\end{tabular}

* $P<0.05$ between Normal and Reverse groups

$\dagger P<0.05$ between second attempt and third attempt in the same group

TABLE III Incidence of post-intubation complications associated with blind tracheal intubation via LMA-Fastrach ${ }^{\mathrm{TM}}$ using conventional tracheal tube.

\begin{tabular}{lll}
\hline & Normal group $(n=120)$ & Reverse group $(n=120)$ \\
\hline Sore throat & $19.2 \%^{*}$ & $9.2 \%$ \\
Hoarseness & $5.0 \%$ & $2.5 \%$ \\
\hline
\end{tabular}

* $P<0.05$ between Normal and Reverse groups.

Placement of the ILMA was successful in all patients and there were no immediate adverse airway events. Various maneuvers were used in $44.6 \%$ of cases to obtain an optimal ILMA position. These included rightward or leftward rotation maneuver (15.8\%), pull-up or push-down maneuvre (19.6\%), change to another size of ILMA (2.9\%), and neck flexion or extension (6.3\%). At no time was $\mathrm{S}_{\mathrm{P}} \mathrm{O}_{2}<95 \%$ during ILMA placement and intubation.

The success rates of blind tracheal intubation via ILMA in both groups are illustrated in Table II. Tracheal intubation was successful in 229 of 240 $(95.4 \%)$ patients. The average number of intubation attempts was 1.37 . There was no difference in the success rates of blind tracheal intubation between the Normal and Reverse groups $(96.7 \%$ and $94.2 \%$ respectively, $P=0.537)$. The first attempt success rate in Reverse group was higher than that in Normal group
( $86.7 \%$ and $75.0 \%$ respectively, $P=0.033$ ). The success rates of blind tracheal intubation at second and third attempt did not differ between two groups.

Changing the tracheal tube curve to the opposite direction at the third attempt increased the success of intubation in Normal group from $85.0 \%$ to $96.7 \%$, $P=0.004$, but not in the Reverse group, $89.1 \%$ to $94.2 \%, P=0.243$. Overall, there were 11 cases of failed blind tracheal intubation in our study and all occurred in the initial nineties. The causes of failure included poor ILMA-larynx alignment (six cases), suspected subglottic stenosis which could not allow passage of $6.0 \mathrm{~mm}$ tracheal tube (one case), elongated and downfolded epiglottis (one case) and unknown (three cases).

The incidence of sore throat was $14.2 \%$ and was higher in the Normal than in the Reverse group $(P=0.042$, Table III). The sore throat was mostly mild in degree, self-limited and needed no medical interventions. The average number of intubation attempts was higher in those with sore throat VAS $>3(1.85 v s$ 1.03). The incidence of hoarseness did not differ between two groups $(P=0.497)$.

\section{Discussion}

In this study, the overall success rate of blind tracheal intubation via an ILMA using a conventional tracheal tube was $95.4 \%$ and was comparable with a previous report $(99.3 \%)$ that used the reusable silicone ILMA tracheal tube. ${ }^{11}$ We used conventional PVC tracheal tubes, instead of autoclavable and reusable silicone ILMA tracheal tubes, because they are less expensive, readily available and disposable. ${ }^{12}$

Many authors have postulated that the steep curvature of the tracheal tube, when inserted in its normal curvature, might have a lower intubation success rate. In our study, the success rates of blind tracheal intubation did not differ between Normal and Reverse groups (96.7\% and $94.2 \%$ respectively). Kapila et al. ${ }^{8}$ and Joo \& Rose $^{12}$ also reported tracheal intubation via ILMA with the tracheal tube inserted in normal and reverse direction respectively. Their overall success rates ranged from $93.0 \%$ to $96.7 \%$ and first attempt success rates varied between $72.0 \%$ and $86.7 \%$. In our study, the first attempt success rate was higher in the Reverse than in the Normal group $(86.7 \%$ vs $75.0 \%$ respectively). In contrast to their multiauthored studies with small case numbers, our study of 240 patients was operated by a single anesthesiologist. We tried to manipulate the ILMA before each attempt at intubation whereas Kapila et al. performed ILMA manipulations (pulling back or pushing down) only if the first intubation attempt failed. Manipulating the ILMA is important, because it improves alignment of the mask 
with the larynx. ${ }^{8}$ Good ventilation via the ILMA indicates good mask-larynx relationship. The efficacy of pulmonary ventilation could be recognized subjectively through manual ventilation and, objectively, through the $\mathrm{CO}_{2}$ exchange on the capnograph and the airway pressure read on monitor. In our study, $54.5 \%$ of the failure was attributed to the inability in obtaining the optimal ILMA position despite efforts in ILMA manipulation.

The incidences of sore throat and hoarseness following standard LMA use are approximately $28.8 \%$ and $11 \% .^{13}$ In our study, the incidences of sore throat and hoarseness were $14.2 \%$ and $3.75 \%$ respectively. Sore throat was associated with an increased number of intubation attempts (1.85 vs 1.03) and tracheal tube curvature. The steep curvature of tracheal tube when it exits the ILMA might be responsible for the higher sore throat score. Though highly successful and without clinical complications, operators should be aware of the potential complications associated with blind intubation via the ILMA. ${ }^{14}$ Caution must be used with passage of PVC tube into the ILMA and the use of force must be avoided to prevent airway trauma.

Blind tracheal intubation via an ILMA has many potential advantages. First, it is not necessary to visualize the larynx during intubation and, consequently, there is negligible cervical spine movement. ${ }^{5}$ Second, ILMA placement needs mouth opening gap of $2 \mathrm{~cm}$. In patients with temporo-mandibular joint disturbance and bad dentition, the trachea could be intubated via the ILMA. Furthermore, placement of the ILMA is independent of factors used to predict difficult intubation. ${ }^{16}$ In addition, the ILMA allows continuous oxygenation during attempts of intubation and hence, less likelihood of desaturation. The ILMA has been reported to solve many problems associated with the difficult airway. ${ }^{2,4-7}$ Personnel should gain experience and become familiar with this new device. It could prove invaluable to emergency room physicians when head and neck manipulation is contraindicated or prohibited 17 and to anesthesiologists in situations where back-up help is not always available. Nevertheless, the addition of cricoid pressure has been shown to impair the ability to intubate through the ILMA. ${ }^{18}$

In conclusion, we recommend the use of the conventional tracheal tube, instead of the autoclavable and reusable ILMA tracheal tube, for tracheal intubation via the ILMA because they are effective, less expensive, disposable, readily available and associated with no clinical complications. To achieve higher success rate of intubation, we advocate the use of the reverse curve at the first attempt and, if it fails, switch to the opposite direction at the second attempt.
References

1 Caplan RA, Posner KL, Ward RJ, Cheney FW. Adverse respiratory events in anesthesia: a closed claims analysis. Anesthesiology 1990; 72: 828-33.

2 Brain AIJ. Three cases of difficult intubation overcome by the laryngeal mask airway. Anaesthesia 1985; 40: 353-5.

3 Parmet JL, Colonna-Romano P, Horrow JC, Miller F, Gonzales J, Rosenberg $H$. The laryngeal mask airway reliably provides rescue ventilation in case of unanticipated difficult tracheal intubation along with difficult mask ventilation. Anesth Analg 1998; 87: 661-5.

4 Joo $H$, Rose $K$. Fastrach - a new intubating laryngeal mask airway: successful use in patients with difficult airways. Can J Anaesth 1998; 45: 253-6.

5 Shung J, Avidan MS, Ing R, Klein DC, Pott L. Awake intubation of the difficult airway with the intubating laryngeal mask airway. Anaesthesia 1998; 53: 645-9.

6 Parr MJA, Gregory M, Baskett PJF. The intubating laryngeal mask. Use in failed and difficult intubation. Anaesthesia 1998; 53: 343-8.

7 Fukutome T. Amaha K. Nakazawa K. Kawamura T. Noguchi $H$. Tracheal intubation through the intubating laryngeal mask airway (LMA-Fastrach ${ }^{\mathrm{TM}}$ ) in patients with difficult airways. Anaesth Intensive Care 1998; 26: 387-91.

8 Kapila A, Addy EV, Verghese C, Brain AIJ. The intubating laryngeal mask airway: an initial assessment of performance. Br J Anaesth 1997; 79: 710-3.

9 Cros AM, Colombani S. Preliminary study of intubation with a new laryngeal mask for difficult intubation. Anesthesiology 1997; 87: A482.

10 Ferson DZ, Supkis DE, Rablfs TF, Jones RL. Evaluation of the intubating laryngeal mask as a primary airway device and a guide for blind endotracheal intubation. Anesthesiology 1997; 87: A485.

11 Brain AIJ, Verghese C, Addy EV, Kapila A, Brimacombe $J$. The intubating laryngeal mask. II: a preliminary clinical report of a new means of intubating the trachea. $\mathrm{Br}$ J Anaesth 1997; 79: 704-9.

12 Joo HS, Rose DK. The intubating laryngeal mask airway with and without fiberoptic guidance. Anesth Analg 1999; 88: 662-6.

13 Figueredo E, Vivar-Diago M, Muñoz-Blanco $F$. Laryngo-pharyngeal complaints after use of the laryngeal mask airway. Can J Anesth 1999; 46: 220-5.

14 Branthwaite $M A$. An unexpected complication of the intubating laryngeal mask. Anaesthesia 1999; 54: 166-7.

15 Nakazawa K, Tanaka N, Ishikawa S et al. Using the intubating laryngeal mask airway (LMA-Fastrach ${ }^{\mathrm{TM}}$ ) for blind endotracheal intubation in patients undergoing cervical spine operation. Anesth Analg 1999; 89: 1319-21. 
16 Brimacombe J. Analysis of 1500 laryngeal mask uses by one anaesthetist in adults undergoing routine anaesthesia. Anaesthesia 1996; 51: 76-80.

17 Schuschnig C, Waltl B, Erlacher W, Reddy B, Stoik W, Kapral S. Intubating laryngeal mask and rapid sequence induction in patients with cervical spine injury. Anaesthesia 1999; 54: 787-97.

18 Harry RM, Nolan JP. The use of cricoid pressure with the intubating laryngeal mask. Anaesthesia 1999; 54: 656-9. 